\title{
Canine thelaziosis in the Czech Republic: the northernmost autochthonous occurrence of the eye nematode Thelazia callipaeda Railliet et Henry, 1910 in Europe
}

\author{
Milan Jirkü ${ }^{1}$, Roman Kuchta ${ }^{1, *}$, Elena Gricaj ${ }^{2}$, David Modrý ${ }^{1,3}$, Kateřina Jirků Pomajbíková ${ }^{1,4^{*}}$ \\ ${ }^{1}$ Institute of Parasitology, Biology Centre, Czech Academy of Sciences, České Budějovice, Czech Republic; \\ ${ }^{2}$ Veterinary Clinic Lhotka, Praha 4, Czech Republic; \\ ${ }^{3}$ Department of Pathology and Parasitology, University of Veterinary and Pharmaceutical Sciences, Brno, Czech Republic; \\ ${ }^{4}$ Faculty of Science, University of South Bohemia, České Budějovice, Czech Republic \\ *corresponding authors
}

\begin{abstract}
The eye nematode Thelazia callipaeda Railliet et Henry, 1910 (Spirurida: Thelaziidae) is a vector-borne zoonotic nematode infecting a range of wild and domestic carnivores as well as humans. It is considered to be a causative agent of emerging and neglected disease and currently invades central part of Europe. Nematodes were collected from the eye of a dog living in Prague, which never travelled outside the Czech Republic. The nematodes were identified based on their morphology and partial sequence of the cox 1 gene as $T$. callipaeda haplotype 1 . This finding represents the northernmost record of autochthonous canine thelaziosis in Europe. The insufficient control of imported animals as well as free movement of dogs and wild carnivores within Europe probably facilitates spreading of T. callipaeda throughout the continent. To better understand the spreading of T. callipaeda and to prevent its zoonotic transmissions, information about the risk of this infection in newly invaded countries should be disseminated not only among veterinarians and physicians, but also within the community of pet owners and hunters.
\end{abstract}

Keywords: Europe, carnivora, Czech Republic, dog, vector-borne disease

The canine eye-worm, Thelazia callipaeda Railliet et Henry, 1910 (Spirurida: Thelaziidae), is a vector-borne zoonotic nematode infecting a range of wild and domestic carnivores, rarely lagomorphs as well as humans (Otranto et al. 2015, Colella et al. 2016, Gama et al. 2016, Mihalca et al. 2016, Ionică et al. 2019). Thelazia callipaeda is known as the 'oriental eye-worm' as it infects primarily dogs in countries of the Far East, where it is also a concern of public health (Colella et al. 2016). Within the last two decades, $T$. callipaeda has been frequently reported in carnivores and occasionally also in humans in several European countries. Its fast spreading throughout Europe is a prominent example of biological invasion (Otranto and Dantas-Torres 2015, Colella et al. 2016).

Canine thelaziosis was first detected in Europe in northern Italy (Rossi and Bertaglia 1989). Since then, the autochthonous occurrence and spreading of $T$. callipaeda were documented in a range of European countries in dogs, but also in humans. Moreover, several imported cases have also been recorded (Table 1). The rapidly increasing num- ber of recorded T. callipaeda infections in Europe over the last decade indicates the gradual spread of this parasite across this continent, which is reflected by the growing awareness of veterinarians and parasitologists (Otranto and Dantas-Torres 2015). The high prevalence of T. callipaeda in dogs in the endemic areas is commonly accompanied by frequent records in red foxes (Otranto et al. 2015), indicating the role of free-ranging carnivores such as cats, wolves, jackals and mustelids as reservoirs of this parasite (Otranto et al. 2015, Mihalca et al. 2016).

The life cycle of T. callipaeda is indirect and involves a non-biting Diptera as an intermediate host, in Europe represented only by the fruit fly Amiota variegata (Fallén, 1823) (Drosophilidae) (Otranto et al. 2006). The insect vector transmits the third-stage (L3) larvae while feeding on ocular secretions of receptive vertebrate definitive hosts (carnivores or humans). The adult nematodes remain localised in the host's eye, producing the first stage (L1) larvae that are eventually ingested by the insect host and develop into L3 larvae, closing the nematode's life cycle. In de-

Address for correspondence: Roman Kuchta and Kateřina Jirků Pomajbíková, Institute of Parasitology, Biology Centre of the Czech Academy of Sciences, Branišovská 1160/31, 37005 České Budějovice, Czech Republic. E-mails: krtek@paru.cas.cz; pomajbikova@paru.cas.cz 

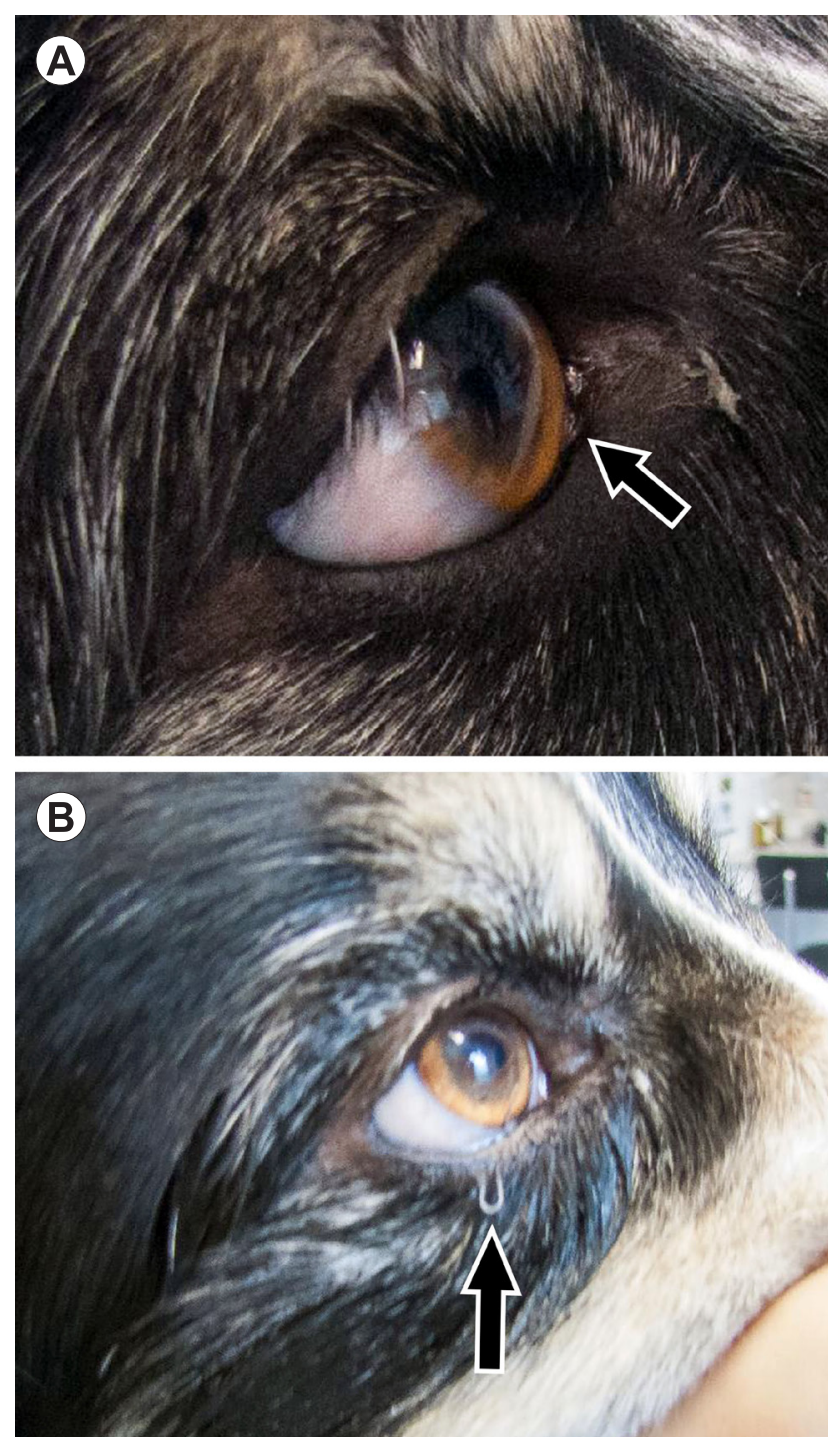

Fig. 1. The patient eye (border collie) with an adult of Thelazia callipaeda Railliet et Henry, 1910. A - slightly visible part of the nematode under third lid (arrow); B - adult worm in the conjunctival sac (arrow).

finitive hosts, adults are commonly found under the lids and nictitating membrane as well as in conjunctival sacs (Otranto et al. 2015). Thus, clinical signs of thelaziosis involve conjunctivitis, epiphora, ocular discharge (often purulent), lacrimation, corneal edema to keratitis or even corneal ulceration (Otranto et al. 2015).

Treatment of thelaziosis is currently based on the manual removal of nematodes directly from the eye of affected dogs, under local anesthesia, and supplemented by an application of spot-on or also oral formulas containing active substances such as imidacloprid, moxidectin or milbemycin (Otranto et al. 2016, Lebon et al. 2019).

The present report describes the occurrence of autochthonous canine thelaziosis in the Czech Republic based on morphological and molecular identification.

\section{MATERIALS AND METHODS}

In July 2018, a six-year-old male border collie was admitted for consultation at the Veterinary Clinic Lhotka (Prague 4, Czech
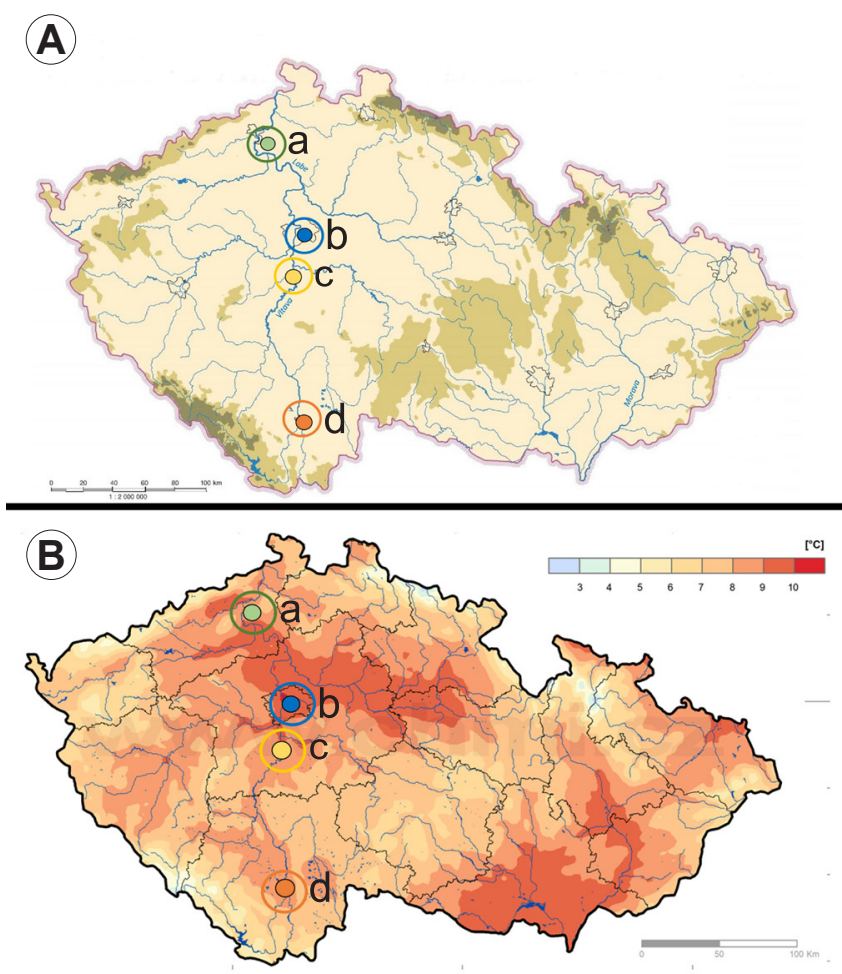

Fig. 2. Distribution of the recorded cases of canine thelaziosis in the Czech Republic. A - localities of the reported cases; B - climatological map of the Czech Republic with temperature scale (adjusted maps from the Czech Hydrometeorological Institute, www.chmi.cz). Abbreviations: a - North-West Bohemia: Litoměřice $\left(50^{\circ} 32^{\prime} \mathrm{N} ; 1^{\circ} 7^{\prime} 55^{\prime \prime} \mathrm{E}\right) ; \mathrm{b}$ - Central Bohemia: Prague $\left(50^{\circ} 05^{\prime} \mathrm{N} ; 14^{\circ} 25^{\prime} \mathrm{E}\right)$ and its surroundings; $\mathrm{c}-$ Central Bohemia: Štěchovice (4951'4"N; 14²4'204"E); d - South Bohemia: České Budějovice (4858'29"N; 14²8'29"E).

Republic) with the unilateral purulent discharge from the right eye. Before this visit, the problem persisted for two weeks when the owner administered boric acid for eye treatment. The dog's orientation and behaviour as well as the pupillary reflex were normal. The fluorescein test was performed. During a closer inspection of the affected eye, $10-15 \mathrm{~mm}$ long nematodes were found under the third lid, which were moving and twisting into a spiral.

Collected nematodes were fixed by hot water and preserved in absolute ethanol for morphological and molecular analyses. For light microscopy examination, the nematodes were cleared with glycerin and studied as temporary slides. Microphotographs were taken using a drawing attachment on an Olympus BX51 microscope (Olympus Corporation, Tokyo, Japan) with differential interference contrast optics. For morphological identification, three worms (one male and two females) which were collected during the first visit of the clinic were used. Identification was done according to the morphological features reported by Skrjabin et al. (1967)

For molecular identification, the total DNA was extracted from one adult worm using $200 \mu \mathrm{l}$ of $5 \%$ Chelex ${ }^{\circledR} 100$ sodium form (Sigma-Aldrich, St. Louis, Missouri, USA), incubated at $60^{\circ} \mathrm{C}$ for $1 \mathrm{hr}$, and then boiled at $90^{\circ} \mathrm{C}$ for $20 \mathrm{~min}$, and stored at $4^{\circ} \mathrm{C}$. PCR amplification of partial cytochrome c oxidase subunit 1 gene (cox1) was performed as described in Folmer et al. (1994) and the product was Sanger-sequenced in GATC Biotech (Konstanz, Ger- 

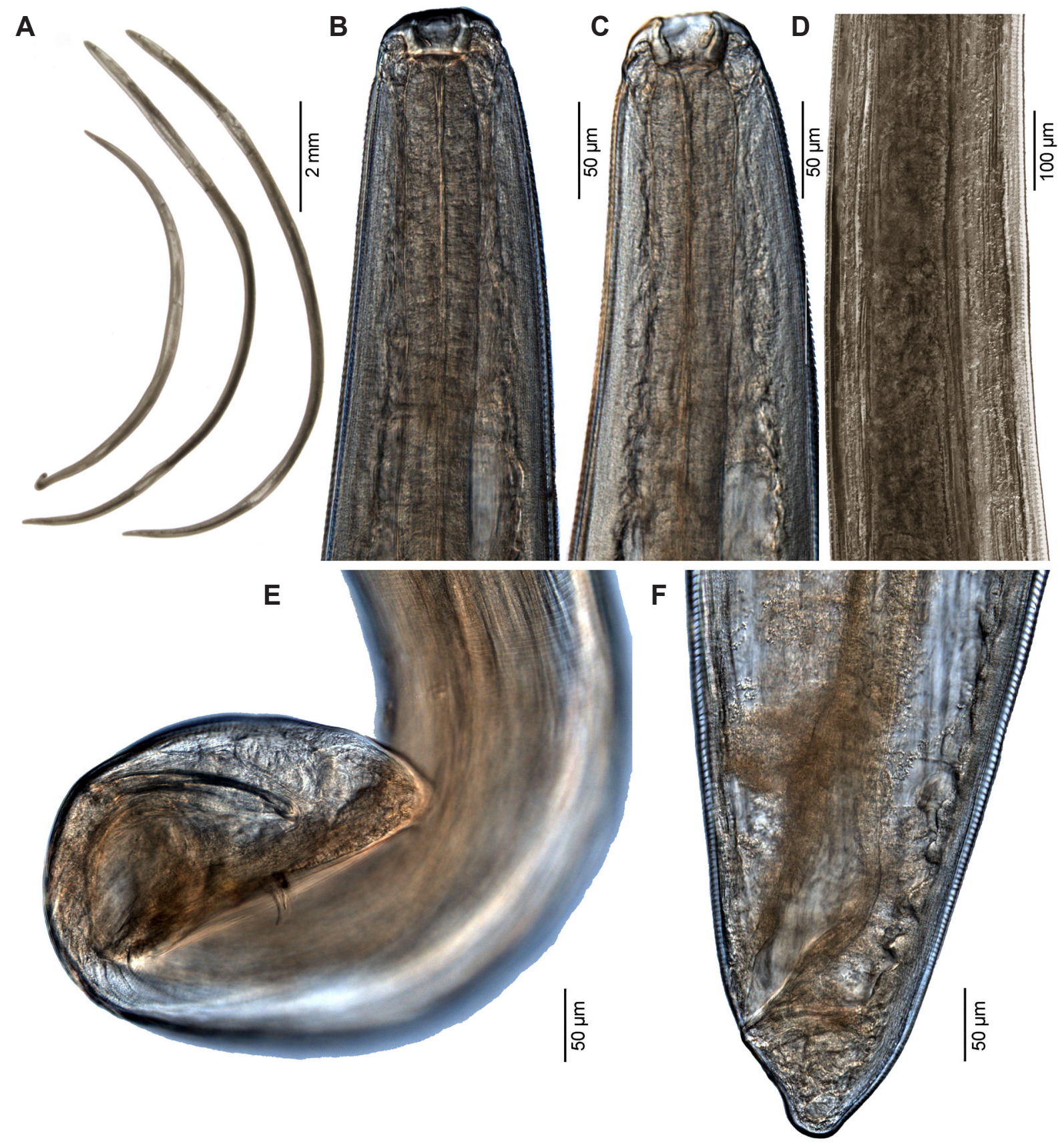

Fig. 3. Microphotographs of Thelazia callipaeda Railliet et Henry, 1910 extracted from the affected eye of border collie from the Czech Republic. A - whole view of one male and two females; $\mathbf{B}, \mathbf{E}$ - detail of the anterior and posterior end of the male; $\mathbf{C}, \mathbf{F}-$ detail of the anterior and posterior end of the female; $\mathbf{D}$ - uterus of female with larvae.

many). Quality of the sequence was checked, the $\operatorname{cox} 1$ sequence was trimmed and subsequently aligned to the representatives of Thelazia callipaeda downloaded from GenBank using Geneious 7.1.9 (http://www.geneious.com). The new sequence was submitted to the GenBank database under accession No. MN310555.

\section{RESULTS}

In total, seven adult nematodes were collected from the dog's affected eye during all visits at the Veterinary Clinic Lhotka in 2018 (Fig. 1). The left eye was without any clinical signs. The affected eye showed catarrhal-purulent discharge and mildly irritated conjunctiva, without blepharospasm or any further pathological findings. The fluorescein test revealed no corneal ulceration. Adult nematodes were removed from the affected eye under local (using procaine) and later also general anesthesia during three visits of the clinic (during July 2018). Then, the dog remained negative during two other consultations at the clinic (in August 2018 and a half year later).

The recent history of the dog, as recalled by the owner, did not include any travel outside the Czech Republic. However, owner reported occasional travels in and around Prague (approx. $50^{\circ} 05^{\prime} \mathrm{N} ; 14^{\circ} 25^{\prime} \mathrm{E}$ ), its surroundings (the Central Bohemia), and in the North-West Bohemia, the Elbe lowland area (specifically Litoměrice area, approx. $50^{\circ} 32^{\prime} \mathrm{N}$; $14^{\circ} 7^{\prime} 55^{\prime \prime} \mathrm{E}$ ) (Fig. 2). The present record of canine 
Table 1. Emergence of Thelazia callipaeda Railliet et Henry, 1910 in Europe between 1989 and 2018 - first reports of thelaziasis across European countries.

\begin{tabular}{|c|c|c|c|}
\hline year & country & origin* & reference \\
\hline 1989 & Italy (northern) & A & Rossi and Bertaglia 1989 \\
\hline 1995-2002 & Italy (southern) & A & Otranto et al. 2003 \\
\hline 2000 & Switzerland & A & Malacrida et al. 2008 \\
\hline 2006 & France & A & Dorchies et al. 2007 \\
\hline 2010 & Germany & A & Magnis et al. 2010 \\
\hline 2010 & Spain & A & Miró et al. 2011 \\
\hline 2011 & Portugal & A & $\begin{array}{l}\text { Rodrigues et al. 2012, } \\
\text { Vieira et al. } 2012\end{array}$ \\
\hline 2011 & Belgium & I & Caron et al. 2013 \\
\hline 2012-2013 & Serbia & A & Gajić et al. 2014 \\
\hline 2011-2014 & $\begin{array}{l}\text { Bosnia \& Herzegovina } \\
\text { Croatia }\end{array}$ & $\begin{array}{l}\text { A } \\
\text { A }\end{array}$ & Hodžíć et al. 2014 \\
\hline 2014 & Greece & A & Diakou et al. 2015 \\
\hline 2015 & Romania & A & Mihalca et al. 2015 \\
\hline 2016 & Austria & A & Hodžíć et al. 2019 \\
\hline 2016 & Hungary & A & Farkas et al. 2018 \\
\hline 2016 & United Kingdom & I & Graham-Brown et al. 2017 \\
\hline 2016 & Bulgaria & A & Colella et al. 2016 \\
\hline 2016-2018 & Slovakia & A & $\begin{array}{l}\text { Cabanová et al. 2017, } \\
\text { Balická et al. } 2018\end{array}$ \\
\hline 2017 & Turkey & A & Eser et al. 2019 \\
\hline 2018 & Czech Republic & $\mathrm{A}, \mathrm{I}$ & Hofmannová et al. 2019 \\
\hline 2018 & Republic of Moldova & A & Dumitrache et al. 2019 \\
\hline
\end{tabular}

thelaziosis in the Czech Republic represents the northernmost autochthonous occurrence of Thelazia callipaeda in Europe so far.

Light microscopy examination of three adult nematodes revealed typical specific feature of T. callipaeda. The male has the precloacal and postcloacal papillae, long left spicule, buccal capsule and transverse striations over the cuticle surface (Fig. 3). The females were gravid with eggs containing larvae (Fig. 3A,C).

The length of the obtained $\operatorname{cox} 1$ sequence was $638 \mathrm{bp}$ long. Multiple sequence alignment with selected representatives of $T$. callipaeda downloaded from GenBank (AM042549-AM042556) resulted in 496bp long alignment and revealed a single nucleotide difference from the T. callipaeda haplotype 1 , contrasting with 7-10 nucleotide differences from the haplotypes 2-8 (Otranto et al. 2005). The sequenced individual was thus identified as $T$. callipaeda haplotype 1, based on the pairwise sequence comparison.

Infected dog (border collie) was treated by a combination of imidacloprid and permethrin (Advantix spot-on for dogs, $10-25 \mathrm{~kg}, 1 \times 2.5 \mathrm{ml}$, Bayer) in three doses within one month after the diagnosis. Later, after removal of all nematodes, the affected eye was treated with Ofloxacinum $3 \mathrm{mg} / 1 \mathrm{ml}$ (Floxal, Chem-pharm Fabrik GmbH). The negativity of the dog was confirmed a half-year later (December 2018) during the regular inspection at the veterinary clinic.

\section{DISCUSSION}

In the past decade there has been a progressive and probably also accelerating invasion of Thelazia callipae$d a$ in the wild and domestic carnivores, which also poses a risk of infection for humans (Otranto and Dantas-Torres
2015). This nematode was apparently imported from Asia to the southern or southeastern Europe towards northwest (Table 1), and it is likely facilitated by common occurrence of its drosophilid vector, Amiota variegata (see Otranto et al. 2006).

The present report describes an autochthonous case of the canine infection with $T$. callipaeda in the Czech Republic. Along with the other reports on its occurrence from neighbouring countries, specifically Germany, Austria and Slovakia (Magnis et al. 2010, Čabanová et al. 2017, Hodžíc et al. 2019), it is evident that populations of T. callipaeda are already established in Central Europe, probably following its spread through southern Europe and the Balkan area (Otranto and Dantas-Torres 2015, Colella et al. 2016) (Table 1).

Given the fact that the infected dog in our study did not have a history of travelling to foreign endemic areas, we consider this to be a sufficient evidence of the autochthonous occurrence of T. callipaeda in the Czech Republic. The recent report by Hofmannová et al. (2019) briefly describes two other cases of canine thelaziosis in the Czech Republic recorded in 2017 and 2018, but without molecular and morphological data. It documents another case of the autochthonous infection of T. callipaeda in a dachshund and also probably imported case of canine thelaziosis in South Bohemia. The latter crossbreed dog had a clear history of traveling to the endemic area of Bulgaria in autumn 2016 (Colella et al. 2016), and later the clinical thelaziosis was diagnosed in winter 2016/2017.

The nematodes obtained from the dog's eye in this study were morphologically and genetically identical with $T$. callipaeda. In general, T. callipaeda shows a high genetic diversity across its original range in eastern Asia, with approximately 20 haplotypes determined so far (Zhang et al. 2018). Contrary to this fact, only haplotype 1 is reported from different European localities, suggesting a single invasion event. Our analysis of a partial sequence of cox 1 demonstrates the haplotype 1 as described previously (Otranto et al. 2005, Mihalca et al. 2015). Unfortunately, the previously described cases of T. callipaeda in the Czech Republic are not molecularly classified (Hofmannová et al. 2019).

The vector of $T$. callipaeda, A. variegata, is broadly distributed across Europe throughout forested areas with deciduous forests (Otranto et al. 2006). Retrospective evaluation of the dog 's movement involved in both autochthonous cases of thelaziosis in the Czech Republic placed a likely origin of these infections to lowland areas of the Central and North-West Bohemia (Fig. 2). The environmental conditions of these areas (i.e., 136-399 metres of altitude, ca. $50 \%$ relative humidity, average daily summer temperature $24^{\circ} \mathrm{C}$ ) together with the presence of deciduous forests correspond well with the occurrence of $A$. variegata in Europe (Palfreyman et al. 2018).

The infection of T. callipaeda in the dog from Prague and its clinical manifestation was recorded in the warmest period of the year, when potential intermediate hosts are most available (Otranto et al. 2006, 2015). The prepatent period of T. callipaeda takes about one month (Otranto 
et al. 2004). Based on this, we assume that infection of the dog from Prague was acquired during spring 2018. For the dog's therapy, the spot-on formulation Advantix ${ }^{\circledR}$ containing a combination of imidacloprid and permethrin was used with regard to the breed predisposition of border collies to MDR1 gene mutation. In this case a use of milbemycin, which is in all recommended therapies for thelasiosis in dogs, is contraindicated (Geyer and Janko 2012).

Despite the increasing number of cases of T. callipae$d a$ infections in domestic and wild animals across Europe, the pathways of spreading of this vector-borne parasitosis remain to be understood. Undoubtedly, free movement of people and their pets within the European Union is a risk factor for the translocation of various diseases and their vectors (e.g., Fooks and Johnson 2015, Gordon et al. 2016). A growing body of the literature demonstrates that wild carnivores play an important role in local epidemiol- ogy of T. callipaeda, especially red foxes appear to be the most suitable reservoir hosts (Otranto and Deplazes 2019).

In addition, cases of thelaziosis were reported also among Eurasian golden jackals (Mihalca et al. 2016), which have rapidly expanded their European range and also reached the Czech Republic (Jirků et al. 2018). Although the role of mobile free-ranging carnivores such as European wolves or jackals cannot be neglected, it is probable that the major driver of the T. callipaeda range expansion is the movement of dogs that travel together with their owners, as well as adoption/importation of dogs from shelters in southeastern Europe.

Acknowledgements. We are indebted to Jan Brabec and Zuzana Lhotská (Institute of Parasitology) as well as Lukáš Hollý (Veterinary Clinic Lhotka) who contributed to the preparation of this study.

\section{REFERENCES}

Balická A., Lapšanská M., Halán M., Trbolová A. 2018: Canine ocular thelaziosis in Slovakia a case report. Folia Vet. 62: 33-38.

Čabanová V., Kocák P., Víchová B., Miterpáková M. 2017: First autochthonous cases of canine thelaziosis in Slovakia: a new affected area in Central Europe. Parasit. Vect. 10: 179.

Caron Y., Premont J., Losson B., Grauwels M. 2013. Thelazia callipaeda ocular infection in two dogs in Belgium. J. Small Anim. Pract. 54: 205-208.

Colella V., Kirkova Z., Fok É., Mihalca A.D., TasićOtašević S., Hodžič A., Dantas-Torres F., Otranto D. 2016: Increase in eyeworm infections in eastern Europe. Emerg. Infect. Dis. 22: 1513-1515.

Diakou A., Di Cesare A., Tzimoulia S., Tzimoulias I., Traversa D. 2015: Thelazia callipaeda (Spirurida: Thelaziidae): first report in Greece and a case of canine infection. Parasitol. Res. 114: 2771-2775.

Dorchies P., Chaudieu G., Siméon L.A., Cazalot G., CanTACESSi C., Otranto D. 2007: First reports of autochthonous eyeworm infection by Thelazia callipaeda (Spirurida, Thelaziidae) in dogs and cat from France. Vet. Parasitol. 149: 294-297.

Dumitrache M.O., Ionică A.M., Voinitchi E., Chavdar N., D'Aмiсо G. 2019. First report of canine ocular thelaziosis in the Republic of Moldova. Parasit. Vect. 12: 505.

Eser M., Miman Ö., Acar A. 2019. Thelazia callipaeda (Railliet and Henry, 1910) case in a dog: first record in Turkey. Kafkas Univ. Vet. Fak. Derg. 25: 131-134.

Farkas R., Takács N., Gyurkovszky M., Henszelmann N., Kisgergely J., Balka G., Solymosi N., Vass A. 2018: The first feline and new canine cases of Thelazia callipaeda (Spirurida: Thelaziidae) infection in Hungary. Parasit. Vect. 11: 338.

Folmer O., Black M., Hoeh W., Lutz R., Vrijenhoek R. 1994: DNA primers for amplification of mitochondrial cytochrome c oxidase subunit I from diverse metazoan invertebrates. Mol. Mar. Biol. Biotechnol. 3: 294-299.

Fooks A.R., JoHnson N. 2015: Jet set pets: examining the zoonosis risk in animal import and travel across the European Union. Vet. Med. (Auck1.) 6: 17-25.

Gajić B., Bogunović D., Stevanović J., Kulišić Z., SimeuNović P., Stanimirović Z. 2014. Canine and feline thelaziosis caused by Thelazia callipaeda in Serbia. Acta Vet. 64: 447-455.

Gama A., Pires I., Canado M., Coutinho T., Lopes A.P., LAtrofa M.S., Cardoso L., Dantas-Torres F., Otranto D. 2016: First report of Thelazia callipaeda infection in wild Euro- pean rabbits (Oryctolagus cuniculus) in Portugal. Parasit. Vect. 9: 236.

Geyer J., Janko C. 2012: Treatment of MDR1 mutant dogs with macrocyclic lactones. Curr. Pharm. Biotechnol. 13: 969-986.

Gordon C.A., McManus D.P., Jones M.K., Gray D.J., Gobert G.N. 2016: The increase of exotic zoonotic helminth infections: the impact of urbanization, climate change and globalization. Adv. Parasitol. 91: 311-397.

Graham-Brown J., Gilmore P., Colella V., Moss L., Dixon C., Andrews M., Arbeid P., Barber J., Timofte D., McGarry J., Otranto D., Williams D. 2017. Three cases of imported eyeworm infection in dogs: a new threat for the United Kingdom. Vet. Rec. 181: 13.

Hodžić A., Latrofa M.S., Annoscia G., Alić A., Beck R., Lia R.P., Dantas-Torres F., Otranto D. 2014. The spread of zoonotic Thelazia callipaeda in the Balkan area. Parasit. Vect. $7: 352$.

Hodžíć A., Payer A., Duscher G.G. 2019: The first autochtonous case of feline ocular thelaziosis in Austria. Parasitol. Res. 118: 1321-1324.

Hofmannová L., Otáhal M., Špírek M., Modrý D. 2019: The eyeworm Thelazia callipaeda: a new pathogen of dogs in the Czech Republic. Vet. Med. 17: 19-22.

Ionică A.M., Deak G., D’Amico G., Stan G.F., Chişamera G.B., Constantinescu I.C., Adam C., Lefkaditis M., Gherman C.M., Minalca A.D. 2019: Thelazia callipaeda in mustelids from Romania with the European badger, Meles meles, as a new host for this parasite. Parasit. Vect. 12: 370.

JiRkŮ M., Dostál D., RobovskÝ J., ŠáLeK M. 2018: Reproduction of the golden jackal (Canis aureus) outside current resident breeding populations in Europe: evidence from the Czech Republic. Mammalia 82: 592-595.

Lebon W., Guillot J., Alvarez M.J., Bazaga J.A., CortesDubly M.L., Dumont P., Eberhardt M., Gomez H., Pennant O., Simeon N., Beugnet F., Halos L. 2019: Prevention of canine ocular thelaziosis (Thelazia callipaeda) with a combination of milbemycin oxime and afoxolaner (Nexgard Spectra $\left.{ }^{\circledR}\right)$ in endemic areas in France and Spain. Parasite 26: 1.

Magnis J., Naucke T.J., Mathis A., Deplazes P., Schnyder M. 2010: Local transmission of the eye worm Thelazia callipae$d a$ in southern Germany. Parasitol. Res. 106: 715-717.

Malacrida F., Hegglin D., Bacciarini L., Otranto D., Nägeli F., Nägeli C., Bernasconi C., Scheu U., Balli A., Marenco M., Togni L., Deplazes P., Schnyder M. 2008: 
Emergence of canine ocular thelaziosis caused by Thelazia callipaeda in southern Switzerland. Vet. Parasitol. 157: 321-327.

Mihalca A.D., D’Amico G., Scurtu I., Chirila R., Mate I.A., IONICA A.M. 2015: Further spreading of canine oriental eyeworm in Europe: first report of Thelazia callipaeda in Romania. Parasit. Vect. 8: 48.

Mihalca A.D., Ionica A.M., D'Amico G., Daskalaki A.A., Deak G., Matei I.A., Simonca V., Iordache D., Modrý D., GHERMAN C.M. 2016: Thelazia callipaeda in wild carnivores from Romania: new host and geographical records. Parasit. Vect. 9: 350 .

Miró G., Montoya A., Montoya A., Hernández L., Dado D., Vázques M.V., Benito M., Villagrasa M., Brianti E., Otranto D. 2011. Thelazia callipaeda: infection in dogs: a newparasite for Spain. Parasit. Vect. 4: 148

Otranto D., Cantacessi C., Dantas-Torres F., Brianti E., Pfeffer M., Genchi C., Guberti V., Capelli G., Deplazes P. 2015: The role of wild canids and felids in spreading parasites to dogs and cats in Europe. Part II: Helminths and arthropods. Vet. Parasitol. 213: 24-37.

Otranto D., Cantacessi C., Testini G., Lia R.P. 2006: Phortica variegata as an intermediate host of Thelazia callipaeda under natural conditions: evidence for pathogen transmission by a male arthropod vector. Int. J. Parasitol. 36: 1167-1173.

Otranto D., Colella V., Crescenzo G., Basano F.S., NazZari R., Capelli G., Petry G., Schaper R., Pollmeier M., Mallia E., Dantas-Torres F., Lia R.P. 2016: Efficacy of moxidectin $2.5 \%$ and imidacloprid $10 \%$ in the treatment of ocular thelaziosis by Thelazia callipaeda in naturally infected dogs. Vet. Parasitol. 227: 118-121.

Otranto D., Dantas-Torres F. 2015: Transmission of the eyeworm Thelazia callipaeda: between fantasy and reality. Parasit. Vect. 8: 273 .

Otranto D., Deplazes P. 2019: Zoonotic nematodes of wild carnivores. Int. J. Parasitol. Parasites Wildl. 9: 370-383.

Otranto D., Lia R.P., Buono V., Traversa D., Giangaspero A. 2004: Biology of Thelazia callipaeda (Spirurida, Thelazii- dae) eyeworms in naturally infected definitive hosts. Parasitology 129: 627-633.

Otranto D., Lia R.P., Traversa D., Giannetto S. 2003 Thelazia callipaeda (Spirurida, Thelaziidae) of carnivores and humans: morphological study by light and scanning electron microscopy. Parassitologia 45: 125-133.

Otranto D., Testini G., De Luca F., Hu M., Shamsi S., GasSER R.B. 2005: Analysis of genetic variability within Thelazia callipaeda (Nematoda: Thelazioidea) from Europe and Asia by sequencing and mutation scanning of the mitochondrial cytochrome c oxidase subunit 1 gene. Mol. Cell. Probes 19: 306313.

Palfreyman J., Graham-Brown J., Caminade C., Gilmore P., Otranto D., Williams D.J.L. 2018: Predicting the distribution of Phortica variegata and potential for Thelazia callipaeda transmission in Europe and the United Kingdom. Parasit. Vect. 11: 272.

Rodrigues F.T., Cardoso L., Coutinho T., Otranto D., DizLopes D. 2012. Ocular thelaziosis due to Thelazia callipaeda in a cat from northeastern Portugal. J. Feline Med. Surg. 14: 952-954.

Rossi L., Bertaglia P.P. 1989: Presence of Thelazia callipaeda Railliet \& Henry, 1910, in Piedmont, Italy. Parassitologia 31: $167-172$.

Skrjabin K.I., Sobolev A.A., Ivashrin V.M. 1967: [Spirurata of animals and man and the disease caused by them. Part 4: Thelazioidea.] In: K.I. Skrjabin (Ed.), Principles of Nematology, Vol XVI. Academy of Sciences of the USSR, Moscow. (In Russian.)

Vieira L., Rodrigues F.T., Costa A., Diz-Lopes D., Machado J., Coutinho T., Tuna J., Latrofa M.S., Cardoso L., Otranto D. 2012. First report of canine ocular thelaziosis by Thelazia callipaeda in Portugal. Parasit. Vect. 5: 124.

Zhang X., Shi Y.L., Han L.L., Xiong C., Yi S.Q., Jiang P., Wang Z.X., Shen J.L., Cui J., Wang Z.Q. 2018: Population structure analysis of the neglected parasite Thelazia callipaeda revealed high genetic diversity in eastern Asia isolates. PLoS Negl. Trop. Dis. 12: e0006165. 